\title{
Characterization of Patients in Fertile Age with Vaginal Flow Syndrome
}

\author{
Dra M Elisa Puentes Rizo', Pedro Rolando Lopez Rodriguez ${ }^{2 *}$, Brenda de la Caridad Zumeta Alfonso ${ }^{3}$, Al \\ Ruben Alfredo Aguiar Puentes ${ }^{4}$ and Al Alejandro Aguiar Puentes ${ }^{5}$ \\ ${ }^{1}$ Specialist of I and II Degree in Comprehensive General Medicine, Cuba \\ ${ }^{2}$ Specialist of I and II in General Surgery, Cuba \\ ${ }^{3}$ First Degree Specialist in Comprehensive General Medicine, Cuba \\ ${ }^{4}$ Medical Student of 6th Year, Cuba
}

${ }^{5}$ Medical Student of 5 th Year, Cuba

*Corresponding author: Pedro Rolando Lopez Rodriguez Specialist of I and II in General Surgery, Consultant Professor and Assistant Researcher, Surgical Clinic Hospital, Cuba.

Received Date: September 23, 2019

Published Date: October 21, 2019

\section{Summary}

Introduction: Vaginal discharge syndrome is an infectious process of the vagina with a florid symptomatology and psychosocial impact on the female population. Objective: To characterize the patients of childbearing age with vaginal discharge syndrome in the Basic Working Group number 2 of the Párraga polyclinic between January and December 2018. Method: Observational, descriptive, and cross-sectional study. 195 patients of childbearing age [between 15 and 49 years of age] of the medical office 10 were studied in the period from January to December 2018 who attended the medical consultation referring to presenting vaginal discharge and / or associated symptoms performing anamnesis, physical examination, and microbiological study.

Result: $32.8 \%$ were between 25 and 29 years old and $41.7 \%$ were black. At least half were $52.3 \%$ pre-university, more than $59.0 \%$ were workers. The majority began sexual intercourse before the age of $20.90 .3 \%$ presented risk factors associated with vaginal discharge. The white, lumpy caseous flow represented $63.1 \%$. At least 9 out of 10 patients presented vaginitis. More than $75 \%$ had Monilia or Gardnerella vaginalis. It was found that $95 \%$ of patients with vaginitis had risk factors.

Conclusion: Patients predominated between the second and third decade of life, of the black race, with the pre-university concluded and workers. The majority were single or accompanied, had begun their sexual life at an early age and presented risk factors. Patients with vaginitis prevailed, with white, lumpy, case-like discharge and with Monilia as the germ causing vaginal discharge. There was a statistically significant relationship between the presence of risk factors and the flow classification.

Keywords: Vaginal discharge syndrome; Risk factor; Sexual risk behavior

\section{Introduction}

Vaginal discharge is a common reason for gynecological consultation at any age, being highly frequent in women of childbearing age, who are concerned about their reproductive health [1]. Vaginal discharge syndrome is an infectious process of the vagina characterized by one or more of the following symptoms: leucorrhoea, vulvar pruritus, burning, irritation, dysuria, dyspareunia, vaginal fetus, determined by the invasion and multiplication of any microorganism and as a result of an environmental imbalance in the vaginal ecosystem [2]. This pathology has a wide range of causal germs and is easy to diagnose and its complications are frequently related to infantile and reproductive maternal morbidity [2,3]. They continue to be a public health problem in the world, they are more frequent in young, single adults and in urban areas, but without anyone with active sex life being exempt from suffering them. They can also cause complications or sequelae in both women and men and children, for example orchiepidimitis, acute pelvic inflammatory disease [hereinafter EIPA], sterility in both sexes, penile or cervix cancer, pregnancy complications, miscarriages, death fetal and / or maternal, premature birth, low birth weight, neonatal infections, 
congenital malformations and at risk of transmitting or becoming infected by the human immunodeficiency virus [hereinafter HIV] as demonstrated by several studies. [4-7]. In medical practice, vaginal infections represent a frequent health problem, representing approximately $75 \%$ of the patients who are consulted by vaginal discharge, according to the number of patients attending the medical consultation of some studies in Venezuela. Taking into account that in the same woman more than one clinical form can coexist [vaginitis and / or cervicitis] and if the gynecological examination does not allow to affirm the presence of a particular causative agent, the treatment should be focused in a syndromic way, at three infections most frequently associated with vaginal discharge syndrome: trichomoniasis, candidiasis and bacterial vaginosis; less frequently, these infections are caused by Neisseria Gonorrhoeae and Clamydia trachomatis $[6,8]$.

Syndromic management represents an alternative to efficiently address this problem and with this type of approach the treatment of the causes most frequently associated with the syndrome in question is achieved and therefore the solution of more than 95\% of cases is guaranteed [9]. The World Health Organization [WHO] estimated that 333 million new cases of curable sexually transmitted diseases annually in people aged 15 to 49, mostly in developing countries, which include member countries of the European community. On the other hand, recent calculations report that each year more than 340 million Cases of curable sexually transmitted infections [STIs] [including only those fungal and parasitic bacterial infections], which have as a manifestation the vaginal discharge syndrome, susceptible to effective treatments and that at least one million infections occur every day. For Latin America and the Caribbean alone, between 35 and 40 million cases of this group of Sexually Transmitted Infection were infected with more than 100 thousand infections per day [4,5]. Vaginal candidiasis is caused by a fungus or yeast found in the vulvo-vaginal mucosa that proliferates favored by broad-spectrum antibiotics, oral contraceptives, pregnancy, menstruation, diabetes mellitus, tight clothing, HIV infection, poor hygiene habits, etc. Women usually present with vulvar irritation and scarce exudate. The vulva may appear inflamed with excoriations and fissures. The vaginal wall may be covered by white, sticky and sticky yeast colonies. This entity began to be considered as a Sexually Transmitted Infection as of 1967 and it is currently accepted that $50 \%$ of the reported cases are the product of sexual contact. Its treatment consists in the use of clotrimazole $100 \mathrm{mg}$, intravaginal twice a day for 3 days or nystatin $100000 \mathrm{U}$ [vaginal ovum] intravaginally, once a day for 14 days [10]. In primary health care services these infections in adolescents are among the first causes of consultation, with a much higher incidence in those young people with active sexual life, although they have also been found in virgin adolescents. [eleven]. Vaginal symptoms are the most frequent reason for gynecology, being responsible for 6 to 10 million medical visits a year in the world [7]. In the United States about $30 \%$ of women of reproductive age have bacterial vaginosis [BV]. Almost $75 \%$ of all adult women have had at least one fungal infection in their lives. About $3 \%$ of women of reproductive age have trichomoniasis. Many women with vaginal infections have no symptoms, for example, only $16 \%$ of women with bacterial vaginosis report having vaginal symptoms, while out of every 100 women who have symptoms, such as pain, itching and discharge; 40 to 45 women have bacterial vaginitis; 20 to 25 women have a fungal infection; 15 to 20 women have trichomoniasis [7-12]. The World Health Organization reported that since 2006 approximately 15,700 women annually go to vaginal health problems in primary care facilities in West African countries [Ghana, Guinea, Mali and Togo], with very low cure rates associated with the costs and non-compliances of the treatment [7]. The results in European countries are also relevant with an estimated 250,000 women who, of childbearing age, go annually to vaginal discharge consultations. Being the most significant figure in women during pregnancy [7].

In Colombia, the prevalence in Colombia of bacterial vaginosis has varied between $9 \%$ in asymptomatic pregnant pregnant women and 30\% in non-pregnant women from the general population [8]. Cuba does not escape this situation, reporting 831787 consultations by these entities [7-12] Havana reports in 2017; 627251 patients assessed by obstetrics consultation, while gynecology attended 208,589 women of childbearing age, if we take into account that approximately $75 \%$ of the consultations are due to vaginal discharge, the total number of patients treated is 156441 [13]. In the Municipality, 19407 patients treated for vaginal infections in the analyzed period are reported [14]. Regarding the Párraga Polyclinic, they behave with 4317 patients assisted in gynecology due to this identity [15].

\section{Methods}

A descriptive and cross-sectional observational study was carried out. 195 patients of childbearing age [between 15 and 49 years of age] of the medical office 10 were studied in the period from January to December 2018 who attended the medical consultation referring to presenting vaginal discharge and / or associated symptoms performing anamnesis, physical examination, and microbiological study.

\section{Inclusion and exclusion criteria}

- Inclusion criteria

Female patients of childbearing age with vaginal discharge who agreed to physical examination with speculum and attended vaginal and endocervical exudate.

\section{- $\quad$ Exclusion criteria}

Patients who do not belong to the health area.

- $\quad$ Pregnant patients.

Patients who have refused to participate in the investigation

\section{Technical and procedures}

Sources of obtaining the information

Application of a data collection form [Annex 1] to the patients from which the related variables were studied. 


\section{Data register}

A database was created in the Microsoft Office Excel 2010 program where the variables contained in the Form being investigated were included.

\section{Processing and analysis of information}

The variables included in the Return were entered into a database in Excel and the statistical processing was carried out in the statistical package Stadistical Package for Social Science for Personal Computer [SPSS-PC] in its version 19.1 for Windows, from which it They will prepare tables that summarize quantitative variables in absolute values and percentages. In addition, statistical tests of independence $\chi 2$ [Chi-Square] will be performed on qualitative variables.

\section{Ethical aspects}

The research was endorsed by the Commission of Medical Ethics in Research of the Faculty of Medical Sciences "Julio Trigo López". No new or experimental medications or techniques were used, which were not yet certified or endorsed for use. No experimental surgical procedures were performed

\section{Result}

(Table 1) The results in relation to the age groups reflect that the majority were found in the group between 25 and 29 years old with 64 cases [32.8\%] and that less than $5.0 \%$ of the patients studied were between 45 and 49 years old (Table 2).

Source: Data collection form.

Table 1: Distribution of patients with vaginal discharge according to age group.

\begin{tabular}{|c|c|c|}
\hline Age Group & No. & $\%$ \\
\hline $15-19$ & 28 & 14,3 \\
\hline $21-24$ & 23 & 11,9 \\
\hline $25-29$ & 64 & 32,8 \\
\hline $30-34$ & 27 & 13,7 \\
\hline $35-39$ & 31 & 15,8 \\
\hline $40-44$ & 13 & 6,7 \\
\hline $45-49$ & 9 & 4,6 \\
\hline Total & 195 & 100 \\
\hline
\end{tabular}

Source: Data collection form.

Table 2: Distribution of patients with vaginal discharge according to apparent skin color.

\begin{tabular}{|c|c|c|}
\hline Appearing Skin Color & No & $\%$ \\
\hline White & 37 & 18,9 \\
\hline Mestizo & 17 & 39,4 \\
\hline Black & 81 & 41,7 \\
\hline Total & 195 & 100 \\
\hline
\end{tabular}

Source: Data collection form.

The results in relation to the apparent skin color reflect that the minority were white 37 cases [18.9\%] and there were no significant differences between mestizo and black (Table 3).
Table 3: Distribution of patients with vaginal discharge according to schooling.

\begin{tabular}{|c|c|c|}
\hline Escolarity & No. & \% \\
\hline Primary & 0 & 0,0 \\
\hline Basic Secondary & 27 & 13,9 \\
\hline Pre Universitary & 102 & 52,3 \\
\hline Average Technician & 46 & 23,5 \\
\hline University & 20 & 10,3 \\
\hline Total & 195 & 100 \\
\hline
\end{tabular}

Source: Data collection form

At least half of the cases studied had completed the preuniversity studies, followed by those with Medium Technician 46 [23.5\%]. No case had primary schooling (Table 4).

Table 4: Distribution of patients with vaginal discharge according to schooling.

\begin{tabular}{|c|c|c|}
\hline Occupation & No. & \% \\
\hline Student & 21 & 22,1 \\
\hline Worker & 137 & 59,0 \\
\hline Unemployed & 37 & 18,9 \\
\hline Total & 195 & 100 \\
\hline
\end{tabular}

Source: Data collection form

The minority were 21 students [22.1\%] and a predominance of female workers 137 [59.0\%] (Table 5).

Table 5: Distribution of patients with vaginal discharge according to schooling.

\begin{tabular}{|c|c|c|}
\hline Civil State & No & \% \\
\hline Single & 88 & 45,1 \\
\hline Married & 34 & 17,5 \\
\hline Accompanied & 73 & 37,4 \\
\hline Widow & 0 & 0,0 \\
\hline Total & 195 & 100 \\
\hline
\end{tabular}

Source: Data collection form

Among the 195 cases studied there were no widows and the majority corresponded to single women and accompanied with at least 8 out of 10 cases (Table 6).

Table 6: Distribution of patients with vaginal discharge age of onset of sexual intercourse.

\begin{tabular}{|c|c|c|}
\hline Starting Age of Sex Relations & No. & $\%$ \\
\hline Under 15 Years Old & 31 & 15,9 \\
\hline 15 to 20 Years & 117 & 60,0 \\
\hline More Than 21 Years & 47 & 24,1 \\
\hline Total & 195 & 100 \\
\hline
\end{tabular}

Source: Data collection form

In the study group, $75.9 \%$ began their sexual relations before the age of 20 (Table 7). Of the total 9 out of 10 presented risk factors under study (Table 8). In 6 out of 10 patients, the flow was white, lumpy with a cheesy appearance and in less than $10 \%$ yellowpurulent or yellow-greenish, fetid or scarce and short-lived (Table 9). 
Table 7: Distribution of patients with vaginal discharge and flow according to the presence of risk factors.

\begin{tabular}{|c|c|c|}
\hline Risk Factors & No. & \% \\
\hline Present & 176 & 90,3 \\
\hline Absent & 19 & 9,7 \\
\hline Total & 195 & 100 \\
\hline
\end{tabular}

Source: Data collection form.

Table 8: Distribution of patients with vaginal discharge according to flow characteristics.

\begin{tabular}{|c|c|c|}
\hline Flow Characteristics & No. & $\%$ \\
\hline White, lumpy cheesy looking & 123 & 63,1 \\
\hline $\begin{array}{c}\text { Homogenous, now adherents } \\
\text { gray-white color, fishy smell }\end{array}$ & 49 & 25,1 \\
\hline Sparkling, yellow-greenish fetid & 2 & 1,1 \\
\hline Yellow -purulentor yellow-greenish fetid & 2 & 1,1 \\
\hline Short duration & 10 & 5,1 \\
\hline Total & 195 & 100 \\
\hline
\end{tabular}

Source: Data collection form.

Table 9: Distribution of patients with vaginal discharge according to classification.

\begin{tabular}{|c|c|c|}
\hline Classification & No. & $\%$ \\
\hline Vaginitis & 183 & 93,8 \\
\hline Cervicitis & 12 & 6,2 \\
\hline Total & 195 & 100 \\
\hline
\end{tabular}

Source: Data collection form.

The majority presented vaginitis 183 patients for 93.8\% (Table 10).

Table 10: Distribution of patients with vaginal discharge according to causative germs.

\begin{tabular}{|c|c|c|}
\hline Causing Germs & No. & \% \\
\hline Monilia & 115 & 58,9 \\
\hline Gardnerella Vaginalis & 38 & 19,4 \\
\hline Chlamydia & 25 & 12,8 \\
\hline Trichomona & 14 & 7,1 \\
\hline Intracellular Diplococcus & 3 & 1,8 \\
\hline Total & 195 & 100 \\
\hline
\end{tabular}

Source: Data collection form.

Patients with Monilia [115; 58.9\%] prevailed, followed by those with Gardnerella vaginalis and Chlamydia [38; 19.4 and 25; 12.8 respectively] (Table 11).

Table 11: Distribution of patients with vaginal discharge according to risk factors and classification.

\begin{tabular}{|c|c|c|c|c|c|c|}
\hline Classification & \multicolumn{2}{|c|}{ Vaginitis } & \multicolumn{2}{c|}{ Cervicitis } & \multicolumn{2}{c|}{ Total } \\
\hline Risk Factors & $\mathrm{n}$ & $\% \mathrm{a}$ & $\mathrm{n}$ & $\% \mathrm{a}$ & $\mathrm{n}$ & $\% \mathrm{~b}$ \\
\hline Present & 174 & 98,9 & 2 & 1,1 & 176 & 90,3 \\
\hline Absent & 9 & 47,4 & 10 & 52,6 & 19 & 9,7 \\
\hline Total & 183 & 93,8 & 12 & 6,2 & 195 & 100 \\
\hline
\end{tabular}

a. Calculated total row.

b. Calculated of the total of the column.

Source: Data collection form X2 $=78.74 \mathrm{gl}[1] \mathrm{p}=0.000$
More than $95 \%$ of the patients studied with vaginitis had risk factors. In the absence of these, more than half had cervicitis. There was a relationship between the variables risk factors and classification with a significance level of $5 \%$ and a degree of freedom.

\section{Discussion}

The development of preventive medicine, with the participation of the doctor and the family nurse, together with the substantial technical and organizational changes to improve the quality of medical care, have forced us to look for more dynamic ways that favor the performance of the medical team. health, among which is the early detection of vaginal infections [16-18]. Vaginal infections affect women of all ages, both those who are sexually active, and those who are not. Most of the visits of adult women to gynecologists and primary care doctors have been more frequent $[19,20]$. The results obtained regarding Vaginal discharge syndrome and age groups were comparatively similar to studies carried out in the province and even in the municipality $[9,49$, 53], with a predominance of women between 20 and 30 years of age. In the study by Vidal Borras et al. Carried out in Caracas, Venezuela [16] as in the present, patients between 25 and 29 years predominated and an inversely proportional relationship between the number of patients affected and the age as defined above. On the other hand, in the study of Álvarez Blanco et al. [20], the age of greatest frequency was between 21 and 25 years. The analysis of the color of the skin and the incidence of Vaginal Flow Syndrome showed a higher frequency between black and mixed race in that order. Probably related to the ethnic characteristics of the place where the study population predominates. No serious studies were found in the literature that address the issue from this point of view, however, we believe that there could be an influence determined by particularities of the sexual characteristics of each race, such as those of black race show a more early and bulky development of secondary sexual characteristics such as breast, hip or butt growth, being able to identify with higher stages of sexual development and anticipate sexual behavior, often at risk. State education, free, equal and compulsory; at least until the ninth grade, which guarantees a level of instruction and education comparable even to that of highly developed nations; It is one of the characteristics of our nation. Therefore, starting in active working life is an option and not an obligation as it is for adolescents in many countries. A female student, usually younger, does not have economic independence and usually has plans to continue her improvement and achieve a job placement according to her level of qualification. In these circumstances and taking into account that the expired institutional educational level was taken into account, it was not surprising to find a majority of pre-university students, followed by those with a mid-level Technician and a basic Secondary School. This result corresponds to those published by the Alan Gulttmacher Institute [21] and the United Nations Population Fund [22]; as with Hurtado Saucedo [23] in his thesis of Specialty in Comprehensive General Medicine, also carried out in our health area between 2013 and 2014. In our country the female population has been increasingly 
incorporated into schooling and the aspiration and need to develop some activity of its own, expanding work options for women. In the present investigation a predominance of the patients linked to some type of work activity was evidenced, as well as in the aforementioned study by Hurtado Saucedo [23], however, this series exceeded ours in percentage terms in terms of the unemployed population. In the study, single and accompanied women represented the majority, corresponding to published national results $[9,16]$. While, the age of onset of sexual intercourse was early in the majority before the age of 20. Series such as that of Ugarte Rodríguez [24] with similar results, discuss how the early onset of sexual intercourse significantly affects the presence of vaginal discharge, because age is a biological factor that influences the presence of it by the constitution The vaginal mucosa and cervical tissue of the young woman make them very susceptible to this entity. Much has been written about the risk factors associated with vaginal discharge syndrome, which constitutes a huge.

Challenge to be faced by professionals dedicated to the promotion and prevention of sexual and reproductive health. In the literature, several articles related mainly to gravity were found, a subject that although useful, for the purposes of this research were taken into account, but this group was intentionally excluded due to the particular characteristics and connotation it has in primary care this combination; Possible subject for future research. It is also relevant in the reading as the risk factors associated with the presence of vaginal discharge are often analyzed independently. It was intended to investigate them, analyze them in terms of their presence or absence because it offers a more accurate understanding of the phenomenon, taking into account that a patient sometimes presented more than one risk factor. In our series, the absence of risk factors represented the minority of cases. These results correspond to those of Cordero Ruiz DM [25], published in Argentina and Escobar Acosta and collaborators published in the Proceedings of the XIII Congress of the Cuban Society of Obstetrics and Gynecology at the Palacio de Convenciones [26-28] where Most of the patients presented at least one of the risk factors analyzed.

Also with studies published in the area of health in question by Hurtado Saucedo [23] and Jira Herrera [28-32] treating these last two thesis studies presented in option to the Specialty of 1st degree in General Medicine Integral. The most frequent clinical manifestation in the present work was lumpy white with a cheesy appearance and the most frequent diagnosis was vaginitis. While the predominant microbiological result was the corresponding one with Monilia followed by Gardnerella vaginalis. Similar results to several published studies such as that of Puentes Rizo EM, Enrique Domínguez and others [9] in "Behavior of the vaginal syndrome in a Párraga office", for whom this clinical manifestation was the second most frequent. And these germs were, although in reverse, also the most frequent, coinciding with our study in which more than $75 \%$ presented this etiology. In their study of cervico-vaginal infections in patients treated in an infertility clinic, Román L, Cervantes M, León A [32-36] also reported as the main clinical manifestations of the homogeneous gray-white vaginal discharge in $40,9 \%$, that although it was not the predominant one in our series, it was similar.
The association between the presence of risk factors and the classification of vaginal discharge in vaginitis or cervicitis was highly significant. Observing that in the absence of these the majority presented cervicitis and its presence the vaginitis. Among other elements related to the fact that the latter are more frequent. The phenomenon addressed imposes a challenge on Public Health in Cuba, to improve the quality of life of women of childbearing age and programs to provide information on the subject must continue to be developed.

\section{Conclusion}

Patients predominated between the second and third decade of life, of the black race, with the pre-university completed and workers. The majority were single or accompanied, had begun their sexual life at an early age and presented risk factors. Patients with vaginitis prevailed, with white, lumpy, case-like flow and with Monilia as the germ that causes vaginal discharge. There was a statistically significant relationship between the presence of risk factors and the flow classification.

\section{Acknowledgement}

None.

\section{Conflicts of Interest}

The authors do not declare having conflicts of interest.

\section{References}

1. Humpiri Paredes L (2012) Vaginal discharge syndrome. Serie en Internet.

2. Cires M, Freijoso E, Silva L, Vergara E, Cutie E, et al. (2014) Guide for the clinical practice of vaginal infections. Rev Cubana Farm 37(1).

3. ACOG (2016) Practice Bulletin. Clinical management guidelines for obstetrician and gynecologist p. 72.

4. Collective of authors (2014) Sexually transmitted infections Guidelines for your treatment. Havana: Ministry of Health of the Republic of Cuba pp. 7-48.

5. Beers MH (2017) The Merck Manual of diagnosis and treatment. 11th ed. Madrid. Elsevier.

6. Cutie Bresler M, Almaguer J, Alvarez M (2015) Bacterial vaginosis at an early age. Cuban Rev Obstet Ginecol 25(3): 174-80.

7. Sherrard J, Donders G, White D, Jensen J, Iusti E (2011) European (IUSTI/ $\mathrm{WHO}$ ) guideline on the management of vaginal discharge, Int J STD AIDS $22(8)$.

8. (2017) Sexual activity in adolescents increases and condom use decreases. American Journal of Obstetrics and Gynecology.

9. Bridges Rizo EM, Enriquez Dominguez B, Jimenez Chacon MC, Lopez Rodriguez P (2009) Behavior of the vaginal discharge syndrome in the office 16, Policlinico Parraga. Cuban Rev Obstet Ginecol 35 (3).

10. Sobel JD (2017) Vaginitis. N Eng J Med 380: 822 - 832.

11. Faro S, Martens M, Maccato M, Hammill H, Pearlman M (2014) Vaginal flora and pelvic inflammatory disease. Am J Obstet Gynecol 169(2): 470474.

12. Fernandez Limia O, Betancourt A, Lesteiro M (2015) Prevalence by immunological diagnosis of Candida spp, Trichomonas vaginalis and Gardnerella vaginalis in pregnant women at the primary level of the health system. Cuban Rev Obstet Ginecol.

13. (2017) Ministry of Public Health. Address of medical records and health statistics. Havana 2018. Statistical Yearbook of Health. 
14. Hamilton G, Falistocco C (2017) Guide for the Management of Sexually Transmitted Infections. Rep. Argentina.

15. (2014) CDC: Guidelines for treatment of Sexually Transmitted Diseases. Guidelines for management of sexually transmitted infections of the World Health.

16. Vidal Borras E (2016) Vaginal discharge syndrome Cuban. Journal of Obstetrics and Gynecology. 36(4): 594-602

17. CDC staff members (2018) Center for Disease Control and Prevention. 2018 Guidelines for treatment of sexually transmitted diseases. MMWR 47: 70-79

18. Biswas MK (2014) Bacterial vaginosis Obstetric and Gynecological Clinics. 1: 165-174.

19. Mc Coy MC, Katz VL, Kuller JA, Killam AP, Livengood CH (2015) Bacterial vaginosis in pregnancy: An approach for the 1990s. Obstetrical and Gynecological Survey 50: 482-488.

20. Alvarez Blanco DA (2014) Vaginal Flow Syndrome Behavior. Dario Calzadilla Angulo Polyclinic.

21. (2016) FNUAP: New campaign against teenage pregnancy. Populi the magazine of UNFPA 28(1): 3

22. (2016) United Nations Children's Fund (UNICEF-2011). Adolescence a time of opportunities. The State of the World's Children 2016. UNICEF.

23. Hurtado Saucedo PM (2014) Characterization of Vaginal Flow Syndrome in CMF 30. Parraga Polyclinic. Orange Creek. Havana. 2013-2014. Completion thesis specializing in Comprehensive General Medicine.

24. Ugarte Rodriguez CJ (2007) Prevalence of cervical-vaginal infections in pregnant women in an obstetric reference hospital in Havana City. Rev Cubana Obstet Ginecol 33 (2).

25. Cordero Ruiz DM, Silva Garcia K, Fuste Pedroso W, Rey Sanchez ML, Visconti Marin C (2017) Vaginal discharge syndrome: A health problem? Rev Sciences.com. Argentina: Edit. Scientist.
26. Escobar Acosta A, Cutie M (2017) Bacterial vaginosis at an early age. Proceedings of the XIII Congress of the Cuban Society of Obstetrics and Gynecology. Convention Palace, Havana

27. Jira Herrera C (2014) Characterization of the Vaginal Flow Syndrome in the Capri Polycline. Arroyo Naranjo Havana. Completion thesis specializing in Comprehensive General Medicine.

28. Roman L, Cervantes M, Leon A, Hernandez E (2017) Cervico-vaginal infections in patients treated in the Infertility clinic. Proceedings of the Xlll Congress of the Cuban Society of Obstetrics and Gynecology. Palace of the Conventions. Havana.

29. Currant D, Fagog, Hansen E, Fellow DO Gardnerella.

30. CDC (2014) Diseases characterized by vaginal diseases treatment guidelines. Recomm Rep 10: 51(RR-6): 42-48.

31. Owen MK, Clenneey TL (2014) Management of vaginitis. AM Farm Physician 70(11): 2125-2132.

32. Leon J (2014) Treaty of Obstetrics. Edit Argentine scientist, Buenos Aires. p. 995.

33. (2016) National Directorate of Epidemiology. Maternal and Child Management. National STI / HIV / AIDS prevention and control program. Syndromic management of vaginal discharge in pregnant women. Ministry of Public Health. Havana, Cuba.

34. Roget M (2015) Vaginal Secretions A sign in the adult woman. Health Vine.

35. Omnia M, Samra (2015) Medicine Specialties. Obtetrics and Gynecology.

36. Jaqulery A, Stylianopoulos A, Hogg G (2014) Vulvovaginitis: clinical features; aetiology and microbiology of the genital tract. Arch Dis Child 81(1): 64-67. 